\title{
A comparative Raman spectroscopic study of natural gas hydrates collected at different geological sites
}

\author{
Bertrand Chazallon ${ }^{\mathrm{a},{ }^{*}}$, Cristian Focsa ${ }^{\mathrm{a}}$, Jean-Luc Charlou ${ }^{\mathrm{b}}$, Christophe Bourry ${ }^{\mathrm{b}}$ and Jean- \\ Pierre Donval ${ }^{\text {b }}$
}

\footnotetext{
a Laboratoire de Physique des Lasers, Atomes et Molécules (PhLAM), Université Lille 1, UMR CNRS 8523, CERLA FR-CNRS 2416, 59655 Villeneuve d'Ascq, France

${ }^{\mathrm{b}}$ Département Géosciences Marines, IFREMER, Centre de Brest, 29280 Plouzané, France
}

*: Corresponding author : Chazallon B., email address : chazallon@phlam.univ-lille1.fr

\begin{abstract}
:
Intact natural gas hydrates recovered on the West African margin in the South Atlantic Ocean (ZaiAngo and Neris II projects) and from the Norwegian Sea (Hakon Mosby Mud Volcano) are investigated by micro-Raman spectroscopy at ambient pressure and low temperature. The gas hydrates collected at different geological sites contain a high methane concentration relative to other minor components that are slightly dispersed in the samples. They crystallize in a type I cubic lattice structure as also confirmed by our preliminary synchrotron diffraction results obtained on the ZaiAngo specimen. However, detailed analysis of selected microscopic areas reveals a variation in the gas distribution among the different specimens. Trace amounts of $\mathrm{CO}_{2}$ and $\mathrm{H}_{2} \mathrm{~S}$ can be identified by their characteristic vibrational signatures in the $1000-3800 \mathrm{~cm}^{-1}$ spectral range. They are found to be coclathrated with methane. Their presence produces a compositional effect on the relative cage occupancy of $\mathrm{CH}_{4}$, as determined from the integrated band intensity ratio corresponding to the molecular stretching modes of methane in the hydrate. The comparative Raman analysis of synthetic hydrates of $\mathrm{H}_{2} \mathrm{~S}, \mathrm{CH}_{4}$ and $\mathrm{CH}_{4}$-deuterohydrates allows the unambiguous assignment of weak band overtones of trapped methane and co-clathrated $\mathrm{H}_{2} \mathrm{~S}$ molecular vibrations.
\end{abstract}

Keywords: Natural clathrate hydrates; $\mathrm{CH}_{4}$-hydrate; $\mathrm{H}_{2} \mathrm{~S}$-hydrate; Micro-Raman spectroscopy 


\section{INTRODUCTION}

Gas hydrates (clathrates) occur naturally on Earth, generally where suitable conditions of high pressure $(\mathrm{p})$ and low temperature $(\mathrm{T})$ prevail. The required $\mathrm{p}-\mathrm{T}$ conditions for their formation are encountered in marine sediments mainly offshore along continental margins, and to a lesser extent in polar regions commonly associated with permafrost (Kvenvolden 1998; Kvenvolden and Lorenson, 2001). They are non-stoichiometric crystalline ice-like compounds with a host lattice composed of hydrogen-bonded water molecules forming cages of different sizes that can accommodate gas molecules (guest). Natural gas hydrates can crystallize in different structure types depending on the nature and size of the guests involved.

The unit cell of a cubic type I structure (sI) with space group $\mathrm{Pm} \overline{3} \mathrm{n}$ comprises $46 \mathrm{H}_{2} \mathrm{O}$ molecules and consists of two small cages (SC) (pentagonal dodecahedral) and six large cages (LC) (tetracaidecahedral) (Stackelberg, 1949). The occluded guest molecules stabilize the host framework and are statistically distributed among the different cages with a maximum of one molecule per cage (van der Waals and Platteuw, 1959). Exception to this rule and the presence of doubly occupied cages has been evidenced experimentally in type II $\mathrm{N}_{2^{-}}, \mathrm{O}_{2^{-}}$and air-hydrates (Kuhs et al., 1997; Chazallon and Kuhs, 2002). This topologically related cubic structure II (with space group $\mathrm{Fd} \overline{3} \mathrm{~m}$ ) consists of $136 \mathrm{H}_{2} \mathrm{O}$ water molecules that form 16 small dodecahedral cages and 8 large hexacaidecahedral cages. Extreme conditions favourable to natural air-hydrates formation are encountered in polar ice cores where air-bubbles trapped in the upper part of the ice sheet slowly transform due to the increasing pressure at high depth (Miller, 1969). Consequently, these hydrates provide a potentially continuous record of past atmospheric composition (Miller, 1969; Shoji and Langway, 1982).

Considerable amounts of natural gases such as methane (a type I hydrate former) are expected to be trapped in the form of clathrates in deep water regions. These compounds represent a considerable energy reserve that corresponds to more than $50 \%$ of the world's recoverable reserve of organic carbon (Lee and Holder, 2001). They are therefore very attractive for the gas industry which starts to provide possible future approaches to their exploitation. In contrast to this attractive approach, their role has been repeatedly quoted in geological hazards (McIver, 1982) or global climate change (Kvenvolden, 1993). Indeed, different speculative scenarios still sustain discussion to explain the possible role of methane hydrate in past and future global climate change (Nisbet, 1990; Paull et al., 1991) due to the potentially enormous "greenhouse" feedback effect of methane (Kvenvolden, 1999). 
The physical properties of natural gas hydrates are important to develop technologies for their exploitation or to establish their formation / dissociation rates and stability fields. Even if laboratory experiments on synthesized gas hydrates are necessary for this purpose, they cannot offer a complete picture of the complex natural processes peculiar to hydrates formation and composition in deep-sea environment. Indeed, the conditions of crystallization and reactants in nature are very different from idealized laboratory experiments and may lead to the formation of a different product. Although new gas hydrate sites are discovered regularly, cores containing intact gas hydrates could only be recovered from 27 oceanic sites (Kvenvolden, 1999), partly due to their instability at ambient temperature and pressure and to the technological difficulties to recover natural solid samples at high depth. In most of the laboratory work on the recovered specimens, the presence of gas hydrates was inferred indirectly from the quantity and nature of the gaseous decomposition products (Kvenvolden et al., 1984; Brooks et al., 1988; Sassen and McDonald, 1994). Only a limited number of analyses have been performed using more direct methods of characterization. They concern intact natural hydrates recovered from sediment cores originating from Gulf of Mexico (Davidson et al., 1986; Yousuf et al., 2004), Blake Ridge (Uchida et al., 1999), Mallik (Tulk et al., 2000), Northeast Pacific continental margin off Oregon (Gutt et al., 1999), Cascadia margin (Yousuf et al., 2004) and more recently Okhotsk Sea (Takeya et al., 2006). Moreover, recent development has been conducted in order to probe in-situ ocean clathrate hydrates via Raman spectroscopy (Hester et al., 2006). All these studies revealed the presence of different structures in these heterogeneous environments and stressed the importance to study the intact solid (un-decomposed and undisturbed in the subsurface). Our previous report was focused on the physical and chemical characterization of intact gas hydrates collected in the CongoAngola basin (Charlou et al., 2004). The present work extends this study to gas hydrates collected in two new areas: the Nigerian and Norwegian margin. A detailed Raman analysis of spectral features corresponding to the internal vibrational motion of the gas molecules is presented. Laboratory specimens of hydrogen sulphide $\left(\mathrm{H}_{2} \mathrm{~S}\right)$-hydrate and methane $\left(\mathrm{CH}_{4}\right)$ hydrate / deuterohydrate are analysed to allow a better identification of the occluded gases and to circumvent ambiguities that may arise in the assignment of weak overtone bands occurring in natural hydrates.

\section{EXPERIMENTAL METHODS}




\subsection{Sample storage and preparation}

Gas hydrates from the Congo-Angola basin (ZAI-ROV cruise, dec. 2000) (Savoye et al., 2000) were collected from a deep giant pockmark ( $\sim 1 \mathrm{~km}$ in diameter $)$ on the ocean floor at $3160 \mathrm{~m}$ water depth in a $12 \mathrm{~m}$ long sediment core. Hydrates up to $10 \mathrm{~cm}$ in diameter were extracted from the core barrel. Smaller specimens were found disseminated over a $50 \mathrm{~cm}$ long zone in the sediment (Charlou et al., 2004). The recovered pieces (massive hydrates) were first stored at $190 \mathrm{~K}$ on board before being shipped to France for further laboratory analysis. The second specimens examined were recovered from the passive Nigerian margin (NERIS II cruise, dec. 2003) $500 \mathrm{~km}$ north from the previous studied area at $\sim 1200 \mathrm{~m}$ water depth in a 1-3 m sediment core. The sample presents some amber colored part on the surface, generally associated with the presence of oil, bacteria and minerals and is embedded in greyish sediments. Macroscopically, they appear as white vein-like forms surrounded by mud (Figure 1A). The third set of samples originated from the Norwegian-Svalbard continental slope (with VICTOR 6000 ROV, 2003) on the Hakon Mosby Mud Volcano (HMMV) and were extracted at $\sim 1260 \mathrm{~m}$ water depth in a $\sim 3 \mathrm{~m}$ long sediment core before being stored at $190 \mathrm{~K}$ on board. Truncated portions of the solid reveal distinct white and greyish-white vein-filling zones (2-3 $\mathrm{cm}$ long) that correspond to the presence of hydrate and ice. This latter proves to be abundant in this sample and may have been induced by hydrate dissociation or gas expansion during recovery (Figure 1B). All these samples are now preserved from decomposition in liquid nitrogen containers.

$\mathrm{CH}_{4}$ and $\mathrm{H}_{2} \mathrm{~S}$-hydrates and $\mathrm{CH}_{4}$-deuterohydrate are produced synthetically in a high pressure stainless steel vessel of low volume capacity $\left(\sim 4 \mathrm{~cm}^{3}\right)$. Ice $\left(\mathrm{H}_{2} \mathrm{O}\right.$ or $\mathrm{D}_{2} \mathrm{O}(99.9 \%$ deuterated, Aldrich)) is ground with a mortar and a pestle at low temperature before being inserted into the high pressure cell. A glove box filled with a dry nitrogen atmosphere is used for preparation of the deuterohydrate in order to limit the H/D exchange. The gas pressure (methane, $99.9 \%$, Air Liquide) is subsequently raised up to 30 bar to initiate $\mathrm{CH}_{4}$-hydrates formation. In this regime the hydrate remains in its stability zone. The vessel is then stored for 11 days in our cold room at $-2{ }^{\circ} \mathrm{C}$. The sample is recovered at low temperature and atmospheric pressure, and stored immediately in the vapour of liquid nitrogen before being analysed by Raman. $\mathrm{H}_{2} \mathrm{~S}$-hydrate is synthesized similarly using a gas pressure $\left(\mathrm{H}_{2} \mathrm{~S}, 99.5 \%\right.$ Air Liquide) of 15 bar. 8 days are allowed for hydrate formation at $-2^{\circ} \mathrm{C}$ in the cold room.

\subsection{Characterization tools}


The natural samples are analyzed by micro-Raman spectroscopy using two different instruments: a XY (DILOR) in Lyon and a LABRAM (Jobin-Yvon) in Lille. The synthetic samples are analyzed using a T64000 (Jobin Yvon) in Lille. About sixty Raman spectra were recorded for each sample. The gas hydrates are handled and quickly transferred in dry liquid nitrogen vapor before being loaded into a pre-cooled LINKAM TMS 600 stage. The working temperature is set between 90 and $130 \mathrm{~K}$ to preserve the samples from decomposition. The analyzed area corresponds to a circular beam spot size of 2 to $5 \mu \mathrm{m}$ in diameter when using the ULWD x 50 Olympus objectives. Typical spectral resolutions of $7 \mathrm{~cm}^{-1}$ (LABRAM) and $1 \mathrm{~cm}^{-1}$ (XY and T64000) are chosen by adjusting the entrance slit width. The laser power at the sample is $\sim 5 \mathrm{~mW}$, thus avoiding sample damage under the laser irradiation. Further details on the loading procedure can be found elsewhere (Chazallon et al., 1998). The peak positions are calibrated using emission lines of a neon lamp. The spectra are then baseline corrected and analyzed with a least-square fitting protocol (PeakFit4) using Voigt area profiles. This procedure allows a precise determination of the integrated band intensities for spectra collected with a high signal to noise ratio.

\section{RESULTS AND DISCUSSION}

\subsection{Cage occupancies and structure}

Spectral features of $\mathrm{CH}_{4}$. A detailed physical and chemical characterization (using various techniques) of the gas hydrate and associated methane plumes from the CongoAngola basin zone has been reported previously (Charlou et al., 2004). Sediment-free hydrates extracted from the inner part of this massive sample have been shown to contain up to $\sim 99.1 \%$ methane. Figure 2 shows typical Raman spectra of the different natural hydrates recorded at atmospheric pressure and $113 \mathrm{~K}$ in the $2875-2935 \mathrm{~cm}^{-1}$ spectral range. They are compared to the Raman spectra of the synthetic $\mathrm{CH}_{4}$-hydrate and free methane gas (Figure 2). Two bands of integrated intensities $\mathrm{I}_{\mathrm{L}}$ and $\mathrm{I}_{\mathrm{S}}$ can be observed respectively at $\sim 2902 \mathrm{~cm}^{-1}$ and $\sim 2915 \mathrm{~cm}^{-1}$, for each gas hydrate. Their widths at half peak height (WHH) are $\sim 3 \mathrm{~cm}^{-1}$ and $\sim$ $4 \mathrm{~cm}^{-1}$ respectively. They correspond to the $\mathrm{C}-\mathrm{H}$ stretching $\left(\mathrm{v}_{1}\right.$ mode) of methane trapped in the type I hydrate structure. In comparison, only a single band corresponding to $v_{1}$ is observed for methane in free gas phase at atmospheric pressure: $\sim 2916 \mathrm{~cm}^{-1}$ with a WHH of $\sim 1.5$ $\mathrm{cm}^{-1}$ (Figure 2). 
The splitting of the $v_{1}$ band in the hydrates can be attributed to a perturbation of the local electrostatic fields produced by the water molecules forming cages of different types ( Tulk et al., 2000). The peak at $\sim 2902 \mathrm{~cm}^{-1}$ can be assigned to the $\mathrm{C}-\mathrm{H}$ stretching of $\mathrm{CH}_{4}$ within the LC whereas the peak at $\sim 2915 \mathrm{~cm}^{-1}$ to the $\mathrm{C}-\mathrm{H}$ stretching of methane within the $5 \mathrm{SC}$, in agreement with previous Raman experiments on synthetic $\mathrm{CH}_{4}$-hydrates (Sum et al., 1997). The "loose-cage-tight-cage" model developed by Pimentel and Charles (1963) and revisited recently by Subramanian and Sloan (2002) corroborates these assignments and qualitatively predicts a more negative frequency shift (relative to the gas phase) for molecules in a "loose cage" environment such as methane in a LC. In contrast, $\mathrm{CH}_{4}$ in the SC is trapped in a "tighter cage" environment, and the band at $\sim 2915 \mathrm{~cm}^{-1}$ is found closer to the $\mathrm{C}-\mathrm{H}$ stretch of the free methane gas. Actually, it is stipulated that the frequency shift relative to the gas phase depends on the location of the guest molecule relative to the water cage wall through the first and second derivatives of the guest-host interaction potential. For certain distances of methane from the wall both derivatives are negative and the stretching frequencies are thus found at lower values when compared to the free gas phase. This applies to the methane hydrogen atoms located at distances satisfying this condition. The tighter SC environment experienced by trapped $\mathrm{CH}_{4}$ when compared to the situation in the $\mathrm{LC}$ leads to a less negative $\mathrm{C}-\mathrm{H}$ frequency shift due to changes in the magnitudes of the potential derivatives.

Methane hydrate occupancy ratios. The integrated intensity ratio $\mathrm{I}_{\mathrm{S}} / \mathrm{I}_{\mathrm{L}}$ is useful to discriminate between the different clathrate structure types and is representative of the cage occupancy ratio. In a type I structure there are three times as many large cages as small cages and the theoretical cage occupancy ratio $\theta_{\mathrm{SC}} / \theta_{\mathrm{LC}}$ is thus obtained by $3 \mathrm{I}_{\mathrm{S}} / \mathrm{I}_{\mathrm{L}}$, where $\theta_{\mathrm{SC}}$ and $\theta_{\mathrm{LC}}$ are the fractional occupancies of the small cage and large cage, respectively (Sum et al., 1997). We assume here that the relative Raman cross sections of $\mathrm{CH}_{4}$ and polarizabilities in both types of cage are similar. These assumptions are however not obvious and the $v_{1}$ splitting of $\sim 12 \mathrm{~cm}^{-1}$ may in turn reflect a perturbation of the $\mathrm{C}-\mathrm{H}$ bond length, i.e. of the scattering cross section, as discussed by Tulk et al. (2000). Using a cross-calibration of Raman and NMR, Wilson et al. (2002) show in turn that the cage occupancy ratio deduced from Raman experiments is quantitative for pure sI methane hydrate. But this situation apparently differs for binary $\mathrm{CH}_{4} / \mathrm{CO}_{2}$ systems, where the occupancy ratio is only found qualitative and varied by $\sim 11 \%$ from the NMR results. This may reflect the influence of $\mathrm{CO}_{2}$ in the neighbouring cages that affects the polarizability derivatives (i.e. also the relative intensities in the Raman 
spectra) of the $\mathrm{CH}_{4}$ molecule. However, this result was obtained for a system with a much higher $\mathrm{CO}_{2}$ concentration than those reported in our study. Therefore, we believe that the small amounts of minor components could only weakly affect the Raman scattering cross section and that $\theta_{\mathrm{SC}} / \theta_{\mathrm{LC}}$ is here quantitative.

For the ZaiAngo hydrate, we refine our previous data treatment and investigate additional data to obtain an experimental $\theta_{\mathrm{SC}} / \theta_{\mathrm{LC}}$ ratio of $0.86 \pm 0.03$ (Table 1). This value is close to the one (0.79) obtained by Uchida and others (1999) on a natural gas hydrate recovered from the ODP Leg 164 at Blake Ridge. A somewhat lower ratio is obtained for the NERIS II - hydrate with $\theta_{\mathrm{SC}} / \theta_{\mathrm{LC}}=0.81 \pm 0.02$. Note that the methane signal can be detected already at the sample surface, thus indicating a rather good preservation of this specimen. $\theta_{\mathrm{SC}} \theta_{\mathrm{LC}}$ for the HMMV hydrate is less precise with a standard deviation relatively higher than the others (Table 1). Hydrates previously recovered from this area have been inferred to contain up to $99.9 \%$ methane (Milkov et al., 2004). Unfortunately, the storage conditions were different for this sample as it was maintained at $\sim 190 \mathrm{~K}$ during several months, before being analyzed in Lille. Therefore, partial decomposition and the release of methane may have occurred during this period. It thus explains the difficulties to locate hydrate-rich zones and the abundant presence of crystalline ice. Moreover, no other gas components can be detected using our Raman technique (detection limit $\lesssim 1 \%$ ) and we have therefore considered that the methane concentration is the one determined by Milkov et al. (2004).

For the synthetic $\mathrm{CH}_{4}$-hydrate a ratio of $\theta_{\mathrm{SC}} / \theta_{\mathrm{LC}}=0.78 \pm 0.02$ is obtained. This result indicates that the SCs are relatively less occupied by methane molecules than the LCs. This view is consistent with a deviation from an ideal Langmuir behaviour for the SC as reported recently on artificial $\mathrm{CH}_{4}$-hydrate (Klapproth et al., 2003). Further, our result is close to that obtained by Uchida et al. (1999) on synthetic hydrates using similar conditions of formation $(29.5$ bar and $273.6 \mathrm{~K})$ with $\theta_{\mathrm{SC}} / \theta_{\mathrm{LC}}=0.77 \pm 0.02$. Note that no significant variation in the ratio is to be expected for higher hydrate formation pressure (up to $\sim 1$ kbar) (Klapproth, 2002). One infers that the slightly higher ratio obtained for the ZaiAngo-hydrate may reflect the presence of other gas components occupying the LC, thus reducing the population of methane in the LC. The ZaiAngo hydrate was previously shown to contain $\sim 1 \% \mathrm{CO}_{2}$ (as also detected by Raman) and other minor gas components such as $\mathrm{C}_{2} \mathrm{H}_{6}(0.043 \%)$ and $\mathrm{H}_{2} \mathrm{~S}$ $(0.02 \%)$ as obtained from gas chromatography analysis of a bulk portion of the specimen (Charlou et al., 2004). As $\mathrm{CO}_{2}$ preferentially partitions into the LC (Kuhs et al., 1998; Udachin et al., 2001), the relative occupancy ratio of methane may be slightly affected in this 
hydrate. The intensity of the $\mathrm{CO}_{2}$ bands is seen to vary slightly from point to point. This means that $\mathrm{CO}_{2}$ is heterogeneously dispersed in the specimen. The standard deviations associated with the estimates of $\theta_{\mathrm{SC}} / \theta_{\mathrm{LC}}$ (Table 1) are related to this variation. In contrast, the Neris II hydrate is shown to consist of almost pure methane (Charlou, private communication) with the presence of trace elements such as $\mathrm{H}_{2} \mathrm{~S}$ (see below), while very weak signals of $\mathrm{CO}_{2}$ can be detected. Its composition thus merely reflects that of a pure methane hydrate. Further work using mixed gas components is needed to confirm the trend observed.

Moreover, on a localized part of the sample, one extra component at $\sim 2889 \mathrm{~cm}^{-1}$ is also observed on the ZaiAngo specimen (Figure 2). This band may be attributed to $\mathrm{C}-\mathrm{H}$ stretching of $\mathrm{CH}, \mathrm{CH}_{2}$ or $\mathrm{CH}_{3}$ groups of aliphatic groups (Ferraro and Nakamoto, 1994) and may characterize the presence of high hydrocarbons or oil and olefins. It is noted that no $\mathrm{CO}_{2}$ can be detected in this zone whereas a slight decrease of $\theta_{\mathrm{SC}} / \theta_{\mathrm{LC}}$ of $\mathrm{CH}_{4}$ is observed $(\sim 0.79)$, thus corroborating our interpretation. The average value of $\theta_{\mathrm{SC}} / \theta_{\mathrm{LC}}$ given in Table 1 for the ZaiAngo specimen does not include this particular case. Moreover, our preliminary structural investigation obtained by synchrotron X-ray diffraction at ambient pressure and $\sim 90 \mathrm{~K}$ reveals the presence of only two independent phases: ice Ih ( $73 \mathrm{wt} . \%)$ and type I ( $27 \mathrm{wt}$. \%) with a lattice constant of $\mathrm{a}=11.869522(23) \AA$ for type I. Further work is in progress on the thermal evolution of the lattice parameters and structural stability of the different hydrates. This will be addressed in a separate contribution.

\subsection{O-H stretching spectral region and weak bands attribution}

Congo-Angola basin (ZaiAngo) and Nigerian margin (NERIS II cruise). The $\mathrm{O}-\mathrm{H}$ spectral region of water at $\sim 3100 \mathrm{~cm}^{-1}$ is displayed in Figure 3. It shows an additional small component at $\sim 3053 \mathrm{~cm}^{-1}$ on the low frequency side of the broad band corresponding to the $\mathrm{O}-\mathrm{H}$ symmetric stretching in the hydrate. This band does not appear on the spectrum of pure ice (Figure 3). Our previous assignment was based on the probable presence of some aromatic groups in small quantities in the environment of the gas hydrates (e.g. benzene and derivatives, olefins) (Charlou et al., 2004). This was in line with previous works on $\mathrm{CH}_{4}$-rich inclusions that attributed the corresponding spectral feature to high hydrocarbons (Wopenka et al., 1990; Kisch and van den Kerkhof, 1991). We propose here another interpretation and provide further rationales for our assignment, which are based on the comparison with our synthetic pure $\mathrm{CH}_{4}$-hydrate / deuterohydrate results. In Figure 3, the O-H spectral region of 
the artificial $\mathrm{CH}_{4}$-hydrate displays a weak band at $\sim 3053 \mathrm{~cm}^{-1}$, in agreement with previous Raman spectra of $\mathrm{CH}_{4}$-hydrate obtained independently (Schicks et al., 2005). Given the high purity of our sample, this band originates from a molecular vibration of methane trapped in the hydrate structure. This is further confirmed on the $\mathrm{CH}_{4}$-deuterohydrate spectra (Figure 3) where the contribution of the water (O-D) stretching is shifted in the $\sim 2300 \mathrm{~cm}^{-1}$ spectral range (not shown on the figure), while the contribution at $\sim 3053 \mathrm{~cm}^{-1}$ still remains. A precise assignment to a methane internal molecular motion is however not straightforward. In comparison, a weak band is observed for methane in the gas phase (Figure 3, Table 2) at $3022 \mathrm{~cm}^{-1}$ that corresponds to the triply degenerate anti-symmetric $\mathrm{C}-\mathrm{H}$ stretching. Moreover, 10 at higher pressure (above 2 bar) a weak overtone starts to grow at $\sim 3070 \mathrm{~cm}^{-1}$ (Brunsgaard Hansen et al., 2001; Hester et al., 2006). On the basis of group theory, this is attributed to an overtone of the doubly degenerate vibration $v_{2}\left(\sim 1540 \mathrm{~cm}^{-1}\right.$, bending) of methane (Table 2$)$. $\mathrm{CH}_{4}$ belongs to the point group $\mathrm{T}_{\mathrm{d}}\left(\mathrm{T}_{\mathrm{d}}\right.$ represents the set of symmetry operations of $\mathrm{CH}_{4}$ and satisfying the properties of a group in mathematical sense (Colthup et al., 1990)). According to $T_{d}$, this mode is active in Raman as deduced from the relation:

$$
\chi_{E}^{2}(R)=\frac{1}{2}\left(\chi_{E}(R) \chi_{E}(R)+\chi_{E}\left(R^{2}\right)\right),
$$

where $\chi_{E}^{2}(R)$ is the character corresponding to the symmetry operation $\mathrm{R}$ (in $\mathrm{T}_{\mathrm{d}}$ ) performed two times. It results that $\mathrm{E}^{2}=\mathrm{A}_{1}+\mathrm{E}$. Since both $\mathrm{A}_{1}$ and $\mathrm{E}$ fundamental vibrations are allowed in Raman, the first overtone of E type normal coordinates is also allowed and should be observed at $2 v_{2}\left(\sim 3070 \mathrm{~cm}^{-1}\right)$ (Brunsgaard Hansen et al., 2001). The perturbed local molecular environment due to water molecules in the hydrate may result in a shift of the frequency at $\sim 3053 \mathrm{~cm}^{-1}$. It should be noted that the fundamental $v_{2}$ is very weak and is not observed by us. The fact that $2 v_{2}$ is easily observable can be explained by a Fermi resonance effect due to a slight interaction of $2 v_{2}$ with the strongest Raman line $v_{1}$ (Herzberg, 1991).

25 This effect results from the small frequency difference between $2 v_{2}$ (overtone) and $v_{1}$ (fundamental) that leads to an enhanced intensity for the bands corresponding to these modes. Other additional effects may contribute to the intensification of this overtone (see below). Therefore, the assignment of the $\sim 3053 \mathrm{~cm}^{-1}$ band to $2 v_{2}$ mode appears to us reliable. In contrast, it should be noted that the trend predicted by the loose-cage-tight-cage model 30 (Subramanian and Sloan, 2002) for low frequency bending vibrations (and thus their overtones) is opposite. Actually, these modes are predicted to shift positively relative to the gas phase. On the basis of this model, one would thus expect a band corresponding to $2 v_{2}$ at 
frequencies higher than $3070 \mathrm{~cm}^{-1}$, a situation that we do not observe. However, it is known that the model, while generally applicable, cannot always explain trends in bending frequencies of the guests (e.g. partial agreement is given in the case of $\mathrm{CO}_{2}$-hydrate and $\mathrm{SO}_{2}$ hydrate) (Subramanian and Sloan (2002)). Furthermore, the model predicts that the band corresponding to $v_{3}$ stretching would be shifted at frequencies lower than $3022 \mathrm{~cm}^{-1}$, however, no band is observed below this value. A comparison with the situation in pure methane gas at high pressure may provide a valuable explanation. In the gas phase, the intensity ratio between the two bands corresponding to the anti-symmetric $v_{3}$ mode and $2 v_{2}$ bending overtone $\left(\mathrm{I}\left(\mathrm{v}_{3}\right) / \mathrm{I}\left(2 v_{2}\right)\right)$ is shown to decrease substantially as pressure of methane increases (Brunsgaard Hansen et al., 2002). Moreover, it is reported that the intensity of the band corresponding to $v_{3}$ mode becomes very weak between 300 and 400 bar and that $\mathrm{I}\left(\mathrm{v}_{3}\right) / \mathrm{I}\left(2 \mathrm{v}_{2}\right)$ is independent of the presence of other natural gas components. Given that the methane density in the recovered hydrate is comparable to that occurring in the gas phase at high pressure, one may expect similarities in the evolution of the $I\left(v_{3}\right)$ band. Thus, it is likely that the Raman band intensity $\mathrm{I}\left(v_{3}\right)$ becomes also very weak in the hydrate and fails to be detected with the present experimental set-up. Although probable, the presence of liquid hydrocarbons in the vicinity of these natural gas hydrates is finally not necessary to explain the spectral feature observed at $\sim 3053 \mathrm{~cm}^{-1}$.

\subsection{Other gas components and weak bands}

$\mathrm{CO}_{2}$-hydrate

The Raman signature of $\mathrm{CO}_{2}$-hydrate can be identified in the ZaiAngo specimen with two bands at $\sim 1377$ and $\sim 1274 \mathrm{~cm}^{-1}$ (Charlou et al., 2004). These bands were attributed to the $v_{1}$ (symmetric stretching $\mathrm{O}-\mathrm{C}-\mathrm{O}$ ) and $2 v_{2}$ (bending overtone) modes of the $\mathrm{CO}_{2}$ molecules trapped in a type I structure, in agreement with Sum et al., 1997. They are shifted relative to the free $\mathrm{CO}_{2}$ gas phase frequencies expected at 1388 and $1285 \mathrm{~cm}^{-1}$ (see inset of Figure 4). For the gas hydrate of the Nigerian margin, traces of $\mathrm{CO}_{2}$ can only be detected on some localized part of the sample thus corroborating a higher $\mathrm{CH}_{4}$ purity for this hydrate.

A weak band is observed at $\sim 2570 \mathrm{~cm}^{-1}$ (Figure 4, Table 2) on the spectrum of the gas hydrate from Congo-Angola basin. This band is close to the spectral region of the molecular vibration ( $\mathrm{H}-\mathrm{S}$ stretching) of $\mathrm{H}_{2} \mathrm{~S}$ or $\mathrm{HS}^{-}$molecules. These species are produced by the oxidation of methane in deep sea environments. Dissolved $\mathrm{HS}^{-}$ions in water are known to 
have a contribution at $\sim 2573 \mathrm{~cm}^{-1}$ and molecular $\mathrm{H}_{2} \mathrm{~S}$ at $2590 \mathrm{~cm}^{-1}$ (Rosasco and Roedder, 1979). An assignment to the $\mathrm{H}_{2} \mathrm{~S}$-clathrate in our case is however not straightforward and should be considered with caution. The important shift $\left(\sim 40 \mathrm{~cm}^{-1}\right)$ relative to the free gas phase of $\mathrm{H}_{2} \mathrm{~S}$ (2611 $\mathrm{cm}^{-1}$ (Schrötter and Klöckner, 1979)) would suggest a rather strong interaction of $\mathrm{H}_{2} \mathrm{~S}$ with the cage wall, possibly arising from the formation to some extent of hydrogen bonding. IR-spectra of $\mathrm{H}_{2} \mathrm{~S}$-clathrate hydrate at $10 \mathrm{~K}$ (Richardson et al., 1985) display a complex band system around $2550 \mathrm{~cm}^{-1}$ and $2610 \mathrm{~cm}^{-1}$, assigned, respectively, to $\mathrm{H}-\mathrm{S}$ stretching in the LC and in the SC. The sharp band system may indicate that $\mathrm{H}_{2} \mathrm{~S}$ assumes two or more different sites or orientations in both the SC and the LC at $10 \mathrm{~K}$. It also differs significantly from the band obtained in the low temperature crystalline $\mathrm{H}_{2} \mathrm{~S}$ phases (Richardson et al., 1985). With a $\mathrm{C}_{2}$ v point group symmetry, all normal vibrational modes of the $\mathrm{H}_{2} \mathrm{~S}$ molecule are active in both IR and Raman. However, the Raman analysis of our synthetic $\mathrm{H}_{2} \mathrm{~S}$-hydrate yields two bands at $\sim 2593 \mathrm{~cm}^{-1}$ and $\sim 2605 \mathrm{~cm}^{-1}$ with a WHH of $\sim 2.5$ $\mathrm{cm}^{-1}$ and $\sim 3 \mathrm{~cm}^{-1}$, respectively (Figure 4, Table 2). Assuming a type I structure in the conditions of their formation (Davidson, 1973), they can be assigned to the H-S stretching in the LC and in the SC, respectively. It is noted that $\mathrm{H}_{2} \mathrm{~S}$ has apparently a higher tendency to be incorporated in the $\mathrm{SC}$ of the type I than $\mathrm{CH}_{4}$ or $\mathrm{CO}_{2}$ as can be deduced from the higher relative cage occupancy ratio (Table 1). The band assignment proposed is in agreement with the one reported previously by Raman on synthetic fluid inclusions of water and $\mathrm{H}_{2} \mathrm{~S}$ (Dubessy et al., 1992). The discrepancies between IR and Raman techniques remain however unexplained. It should be noted that a different protocol was used to form $\mathrm{H}_{2} \mathrm{~S}$-hydrate in the IR experiment. The crystalline compound results from the vapour co-deposition at low temperature of an appropriate water/gas ratio and subsequent thermal treatment between 130 $\mathrm{K}$ and $10 \mathrm{~K}$. Further work using Raman and samples produced by co-deposition will help to elucidate these distinct spectral features.

For comparison, the spectrum of the gas hydrate from Nigerian margin (Neris II) is displayed in Figure 4. Two bands are observed at $\sim 2570 \mathrm{~cm}^{-1}$ and $\sim 2593.5 \mathrm{~cm}^{-1}$. The band at $\sim 2593.5 \mathrm{~cm}^{-1}$ match reasonably well with the band assigned to the $\mathrm{H}-\mathrm{S}$ stretching of $\mathrm{H}_{2} \mathrm{~S}$ in the LC of the synthetic $\mathrm{H}_{2} \mathrm{~S}$-hydrate. The absence of the band at $\sim 2605 \mathrm{~cm}^{-1}$ in the natural 30 sample may come from the low concentration of enclosed $\mathrm{H}_{2} \mathrm{~S}$ and a low signal/noise ratio. One deduces that $\mathrm{H}_{2} \mathrm{~S}$-hydrate is present at low concentration in this specimen and $\mathrm{H}_{2} \mathrm{~S}$ is coclathrated with methane in a type I structure. 
The $2570 \mathrm{~cm}^{-1}$ band common to all natural hydrates may in turn originate from methane. As discussed above, no peak originating from sulfur compounds matches exactly this band. Although the contribution of $\mathrm{HS}^{-}$ions dissolved in the water structure cannot be completely ruled out due to unknown pressure effects, evidence exists that a non fundamental molecular vibration of methane may correspond to this peak. In Figure 4, the spectrum of our pure synthetic $\mathrm{CH}_{4}$-hydrate presents also a weak signal at $2570 \mathrm{~cm}^{-1}$. In the free gas phase, $\mathrm{CH}_{4}$ has no fundamental vibration in this region, but a weak band is though observed at 2580 $\mathrm{cm}^{-1}$. It is tempting to attribute this vibration to the first overtone of $v_{4}\left(1306 \mathrm{~cm}^{-1}\right)$ bending mode of $\mathrm{CH}_{4}$. Note that $v_{4}$ is very weak and is not observed by us in the methane gas phase. According to group theory, $v_{4}$ is triply degenerate and corresponds to the symmetry species $F_{2}$ (Colthup et al., 1990). We derived the spectroscopic activity of the triply degenerate overtone using the relation:

$$
\chi_{F 2}^{2}(R)=\frac{1}{3}\left(2 \chi_{F 2}(R) \chi_{F 2}(R)+\chi_{F 2}\left(R^{2}\right)\right),
$$

where $\chi_{F 2}^{2}(R)$ is the character of the overtone $2 v_{4}$. Using this expression, the symmetry species of the excited state is determined as: $\left(F_{2}\right)^{2}=A_{1}+E+F_{2}$. All these modes being Raman active in $T_{d}$, the overtone $2 v_{4}$ will also be active in Raman. Thus, evidence exists that the band at $2580 \mathrm{~cm}^{-1}$ may correspond to $2 \mathrm{v}_{4}$ and that this band is apparently downshifted to $2570 \mathrm{~cm}^{-1}$ in the hydrate due to the perturbation by water molecules. It should be noted that the assignment of triply degenerate overtones is uncertain because of anharmonicity that may result in a splitting of overtones in sub-bands whose separations and relative intensities are difficult to predict. Further work using methane isotopes is certainly needed and may help in a more definitive assignment. In contrast to $v_{1}$, no splitting due to trapping of $\mathrm{CH}_{4}$ in the different cages is observed in the $2 v_{4}$ spectral region. This may be rationalized by the low signal to noise ratio that prevents the observation of this mode. It should be noted that $2 v_{4}$ (assuming a bending overtone assignment) is expected to be shifted positively in respect to the free gas phase according to the loose-cage - tight-cage model. As discussed above in the case of $2 v_{2}$, the model is apparently unable to explain the trends in the bending frequencies of the guests and thus of the bending overtones of methane. Further work is in progress to relate our Raman results to crystallographic and thermodynamic measurements in order to give a better account of the formation and dissociation mechanisms of natural gas hydrates. 


\section{SUMMARY}

Micro-Raman spectroscopy proves to be a powerful tool to analyze detailed spectral features characterizing the enclathrated gas components in the natural gas hydrates. The gas hydrates collected in the different geological settings (geographically and chemically) contain a high methane concentration relative to other minor components that are found slightly dispersed in the samples. They crystallize in a type I cubic lattice structure, as also confirmed from our preliminary synchrotron diffraction results obtained on the ZaiAngo specimen. Presence of type I structure rather indicates a microbial origin for methane, at least for the specimens originating from the West African coast as also corroborated from our previous work (Charlou et al., 2004). However, detailed analysis of microscopic selected areas reveals a variation in the gas distribution among the different specimens. Additional components (like $\mathrm{CO}_{2}$ and/or $\mathrm{H}_{2} \mathrm{~S}$, high hydrocarbons) can be spectroscopically identified in the samples recovered from the West African coast. Evidence exists that their presence has a compositional effect on the relative cage occupancy of the methane. The $\mathrm{H}_{2} \mathrm{~S}$ and $\mathrm{CH}_{4}$ spectral contributions in the natural hydrates have been determined by comparison with synthetic hydrates of pure $\mathrm{H}_{2} \mathrm{~S}, \mathrm{CH}_{4}$ (from both $\mathrm{H}_{2} \mathrm{O}$ and $\mathrm{D}_{2} \mathrm{O}$ hosts). Two bands are assigned to overtones of bending of enclathrated $\mathrm{CH}_{4}$ and are distinct from that of enclathrated $\mathrm{H}_{2} \mathrm{~S}$. These results may also be useful to discriminate between the contribution of occluded free methane gas and/or other higher hydrocarbons during analysis of natural hydrates on the sea floor with field Raman spectrometry.

\section{ACKNOWLEDGMENTS}

The Centre d'Etudes et de Recherches Lasers et Applications (CERLA) is supported by the Ministère chargé de la Recherche, the Région Nord-Pas de Calais, and the Fonds Européen de Développement Economique des Régions. Gas hydrates from the Congo-Angola basin and Nigerian margin studied here were collected during the ZAIANGO (ZaiROV-Leg 2

30 Fuides-December 2000), and Neris II Projects funded by TOTAL and Ifremer. Gas hydrates from the Norvegian margin were collected on Hakon Mosby Mud Volcano during the ARK XIX/3b expedition in 2003, a cooperation between Alfred Wegener Institute and Ifremer. Thanks go to H. Ondreas (ZaiAngo-Leg 2 Fluides), M. Voisset and G. Floch (NERIS II) and M. Klages and E. Sauter (ARK XIX/3b) and to the scientific parties of these three cruises 
who's permitted the collection of gas hydrate specimens. We are grateful to the captain, officers, crew of the different research vessels and people in charge on board of sediment coring. We are indebted to P. Dhamelincourt and J. Laureyns from LASIR (Lille), B. Champagnon from LPCML (Lyon) for valuable discussions and time accorded on the LABRAM and XY-DILOR. We are grateful to J. M. Barnola (LGGE) for providing the high pressure cell for the gas hydrate synthesis. K. C. Hester and E. D. Sloan (CHR, Colorado School of Mines) are acknowledged for helpful discussions. The reviewers are acknowledged for their helpful suggestions.

\section{REFERENCES}

Brooks J.M., Kennicutt M.C., Fay R.R., McDonald T.J., 1988, Thermogenic gas hydrates in the gulf of Mexico, Science 225, 409.

Brunsgaard Hansen S., Berg R.W., Stenby E.H., 2001, Raman spectroscopic studies of methane-ethane mixtures as a function of pressure, Appl. Spectrosc. 55, 745.

Brunsgaard Hansen S., Berg R.W., Stenby E.H., 2002, How to determine the pressure of a methane-containing gas mixture by means of two weak Raman bands, $v_{3}$ and $2 v_{2}$, J. Raman Spectrosc., 33, 160.

Charlou J.L., Donval J.P., Fouquet Y., Ondreas H., Knoery J., Cochonat P., Levaché D., Poirier Y., Jean-Baptiste P., Fourré E., Chazallon B., 2004, Physical and chemical characterization of gas hydrates and associated methane plumes in the Congo-Angola basin, Chem. Geol., 205, 405.

Chazallon B., Champagnon B., Panczer G., Pauer F., Klapproth A., Kuhs W.F., 1998, MicroRaman analysis of synthetic air-clathrates, Eur. J. Min. 10, 1125.

Chazallon B., Kuhs W.F., 2002, In situ structural properties of $\mathrm{N}_{2^{-}}, \mathrm{O}_{2^{-}}$and air-clathrates by neutron diffraction, J.Chem.Phys. 117, 308.

Colthup N.B., Daly L.H., Wiberley S.E., 1990, Introduction to infrared and Raman spectroscopy, $3^{\text {rd }}$ edition, Acad. Press, New York.

Davidson D.W. 1973, in Water - A comprehensive Treatise, Ed. F. Franks, Plenum Press, New York, vol 3.

40 Davidson D.W., Garg S.K., Gough S.R., Handa, Y.P., Ratcliffe, C.I., Ripmeester J.A., Tse J.S., 1986, Laboratory analysis of a naturally occurring gas hydrate from sediment of the Gulf of Mexico, Geochim. Cosmochim. Acta, 50, 619. 
Dubessy J;, Boiron M.C., Moissette A., Monnin C., Sretenskaya N., 1992, Determination of water, hydrates and $\mathrm{pH}$ in fluid inclusions by micro-Raman spectroscopy, Eur. J. Min. 4, 885.

5

Gutt C., Asmussen B., Press W., Merkl C., Casalta H., Greinert J., Bohrmann G., Tse J.S., Hüller A., 1999, Quantum rotations in natural methane-clathrates from the Pacific sea-floor, Europhys. Lett., 48, 269.

Herzberg G., 1991, Molecular spectra and Molecular structure Vol II, Infrared spectra and

Raman spectra of Polyatomic molecules, Krieger publishing company Malabar, Florida.

Hester K.C., White S.N., Peltzer E.T., Brewer P.G., Sloan E.D., 2006, Raman spectroscopic measurements of synthetic gas hydrates in the ocean, Mar. Chem. 98, 304.

Kisch H.J., van den Kerkhof A.M., 1991, $\mathrm{CH}_{4}$-rich inclusions from quartz veins in the Valleyand-Ridge province and the anthracite fields of the Pennsylvania Appalachians, Am. Mineral. $76,230$.

Klapproth A., 2002, Strukturuntersuchungen an Methan-und Kohlenstoffdioxid-ClathratHydraten, Doktorarbeit, Universität Göttingen.

Klapproth A., Goreshnik E., Staykova D., Klein H., Kuhs W.F., 2003, Structural studies of gas hydrates, Can. J. Phys., 81, 503.

Kuhs W.F., Chazallon B., Radaelli P.G., Pauer F., 1997, Cage occupancy and compressibility of deuterated $\mathrm{N}_{2}$-clathrate hydrate by neutron diffraction J. Incl. Phenom. 29, 65 .

Kuhs W.F., Chazallon B., Klapproth A., Pauer F., 1998, Filling isotherms in clathrate hydrates, Rev. High Pressure Sci. Technol., 7, 1147.

Kvenvolden K.A., Claypool G.E., Threlkeld C.N., Sloan E.D., 1984, Geochemistry of a naturally occuring massive marine gas hydrate, Org. Geochem., 6, 703.

Kvenvolden K.A., 1993, Gas hydrates-Geological perspective and global change, Rev. Geophys. 31, 173.

Kvenvolden K.A., A primer on the geological occurence of gas hydrate. In: Henriet J.P. \& Mienert J. (Eds)., 1998, Gas hydrates: Relevance to world margin stability and climate change. Geological Society, London, special publication, 137, 9-30.

Kvenvolden K.A., 1999, Potential effects of gas hydrate on human welfare, Proc. Natl. Acad. Sci., USA, 96, 3420.

Kvenvolden K.A. \& Lorenson TD, 2001, The global occurence of natural gas hydrate. In Paull C.K., Dilllon W.P. (Eds), Natural gas hydrates. Occurrence, Distribution and Detection. Geophysical monograph, vol. 124. AGU Columbia, pp 3-18.

Lee S.-Y., Holder G., 2001, Methane hydrates potential as a future energy resource, Fuel Processing Technology 71, 181-186.

Ferraro J.R. and Nakamoto K. 1994, Raman spectrometry, Academic Press, Inc., London. 
McIver R.D., 1982, Role of naturally occurring gas hydrates in sediment transport AAPG Bulletin, 66, 789 .

5 Milkov A.V., Vogt P.R., Crane K., Lein A.Y., Sassen R., Cherkashev G.A., 2004, Geological, geochemical, and microbial processes at the hydrate-bearing Hakon Mosby mud volcano: a review, Chem. Geol. 205 (3-4), 347.

Miller S.L., 1969, Clathrate hydrates of air in Antarctic ice, Science, 134, 489.

Nakamoto K., 1978, Infrared and Raman Spectra of Inorganic and Coordination Compounds, $3^{\text {rd }}$ ed., J. Wiley \& Sons, New York.

Nisbet E., 1990, The end of the ice age, Can. J. Earth Sci. 27, 148

15

Paull C.K., Ussler W., Dillon W., 1991, Is the extent of glaciation limited by marine gashydrates, Geophys. Res. Lett. 18, 432.

Pimentel G.C., Charles S.W., 1963, Infrared spectral perturbations in matrix experiments, 20 Pure Appl. Chem. 7, 111.

Richardson H.H., Wooldridge P.J., Devlin J.P., 1985, FT-IR spectra of vacuum deposited clathrate hydrates of oxiran $\mathrm{H}_{2} \mathrm{~S}, \mathrm{THF}$, and ethane, J. Phys. Chem., 83(9), 4387.

Rosasco G.J., Roedder E., 1979, Application of a new Raman microprobe spectrometer to non-destructive analysis of sulphate and other ions in individual phases in fluid inclusions in minerals, Geochim. Cosmochim. Acta 43, 1907.

Sassen R., McDonald I.R. 1994, Evidence of structure H hydrate, Gulf of Mexico continental slope, Org. Geochem., 22, 1029.

Savoye B., Cochonat P., et al., 2000, Structure et évolution récente de l'éventail turbiditique du Zaïre: premier résultats scientifiques des missions d'explorations ZaïAngo 1 et 2 (marge Congo-Angola). C. R. Acad. Sci., Ser. 2, Sci., Terre Planètes, 331, 211-220.

Schicks J., Erzinger J., Ziemann M.A., 2005, Raman spectra of gas hydrates - differences and analogies to ice Ih and (gas saturated) water. Spectrochim. Acta, Part A 61, 2399

Schrötter H.W. and Klöckner H.W., 1979, Raman scattering cross sections in gases and liquids, In: "Raman spectroscopy of gases and liquids", A. Weber, ed., Springer-Verlag, Berlin, 123-137.

Shoji H., and Langway C.C., 1982, Air hydrate inclusions in fresh ice core, Nature, 298, 548.

Stackelberg M.v., 1949, Feste Gashydrate, Naturwissenshaften; 36327.

Subramanian S., Sloan E.D., 2002, Trends in vibrational frequencies of guests trapped in clathrate hydrate cages, J. Phys. Chem. B, 106, 4348. 
Sum A.K., Burruss R.C., Sloan E.D., 1997. Measurements of clathrate hydrates via Raman spectroscopy, J. Phys. Chem. B, 101, 7371.

Takeya S., Kida M., Minami H., Sakagami H., Hachikubo A., Takahashi N., Shoji H.,

5 Soloviev V., Wallmann K., Biebow N., Obzhirov A., Salomatin A., Poort J., 2006, Structure and thermal expansion of natural gas clathrate hydrates, Chem. Eng. Sci. 61, 2670.

Tulk C.A., Ripmeester J.A., Klug D.D., 2000, The application of Raman spectroscopy to the study of gas hydrates, NYAS 912, 859.

Uchida T., Hirano T., Ebinuma T., Narita H., Gohara K., Mae S., Matsumoto R., 1999, Raman spectroscopic determination of hydration number of methane hydrates, Env. Energy Eng., 45, 12.

15 Udachin K.A., Ratcliffe C.I., Ripmeester J.A., 2001, Structure, composition and thermal expansion of $\mathrm{CO}_{2}$ hydrate from single crystal X-ray diffraction measurements, J. Phys. Chem. B 105, 4200.

Waals van der J.H., Platteuw J.C., 1959, Clathrate Solutions, Adv. Chem. Phys. Vol 2.

Wilson, L.D., Tulk C.A., Ripmeester J.A., Instrumental techniques for the investigation of methane hydrates: cross-calibrating NMR and Raman spectroscopy data, Proceedings of the Fourth International Conference on Gas Hydrates, Yokohama, 2002

25 Wopenka B., Pasteris J.D., Freeman J.J., 1990, Analysis of individual fluid inclusions by Fourier transform infrared and Raman microspectroscopy, Geochim. Cosmochim. Acta 54, 519.

Yousuf M., Qadri S.B., Knies D.L., Grabowski K.S., Coffin R.B., Pohlman J.W., 2004, Novel results on structural investigations of natural minerals of clathrate hydrates, Appl. Phys. A, $78,925$. 
FIGURE 1: Recovered gas hydrate samples from the Nigerian margin (A) and Norvegian site (B). The white and greyish-white vein fillings correspond to ice and hydrate mixtures embedded in the solid mud sediment

\section{FIGURE 1}

10

A

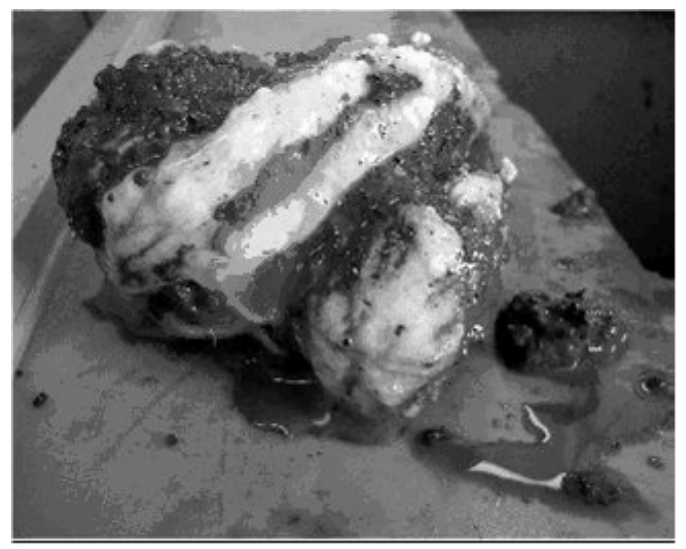

B

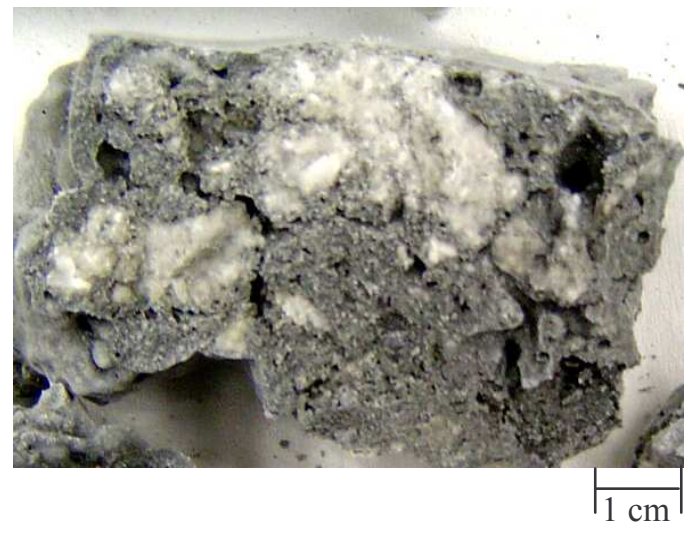


FIGURE 2: Comparison between Raman spectra of natural hydrates collected at different sites and synthetic $\mathrm{CH}_{4}$-hydrate. The spectral region corresponds to the $\mathrm{C}-\mathrm{H}$ stretching of methane. The characteristic twin bands at $\sim 2902$ and $\sim 2915 \mathrm{~cm}^{-1}$ are attributed to $\mathrm{CH}_{4}$ trapped in the large and small cage of the type I structure. C-H stretching of methane gas

5 (atmospheric pressure) with a unique band at $\sim 2916 \mathrm{~cm}^{-1}$ is plotted for comparison. Note the occurrence of a component at $\sim 2889 \mathrm{~cm}^{-1}$ attributed to $\mathrm{C}-\mathrm{H}$ stretching of $\mathrm{CH}, \mathrm{CH}_{2}, \mathrm{CH}_{3}$ group of aliphatic groups.

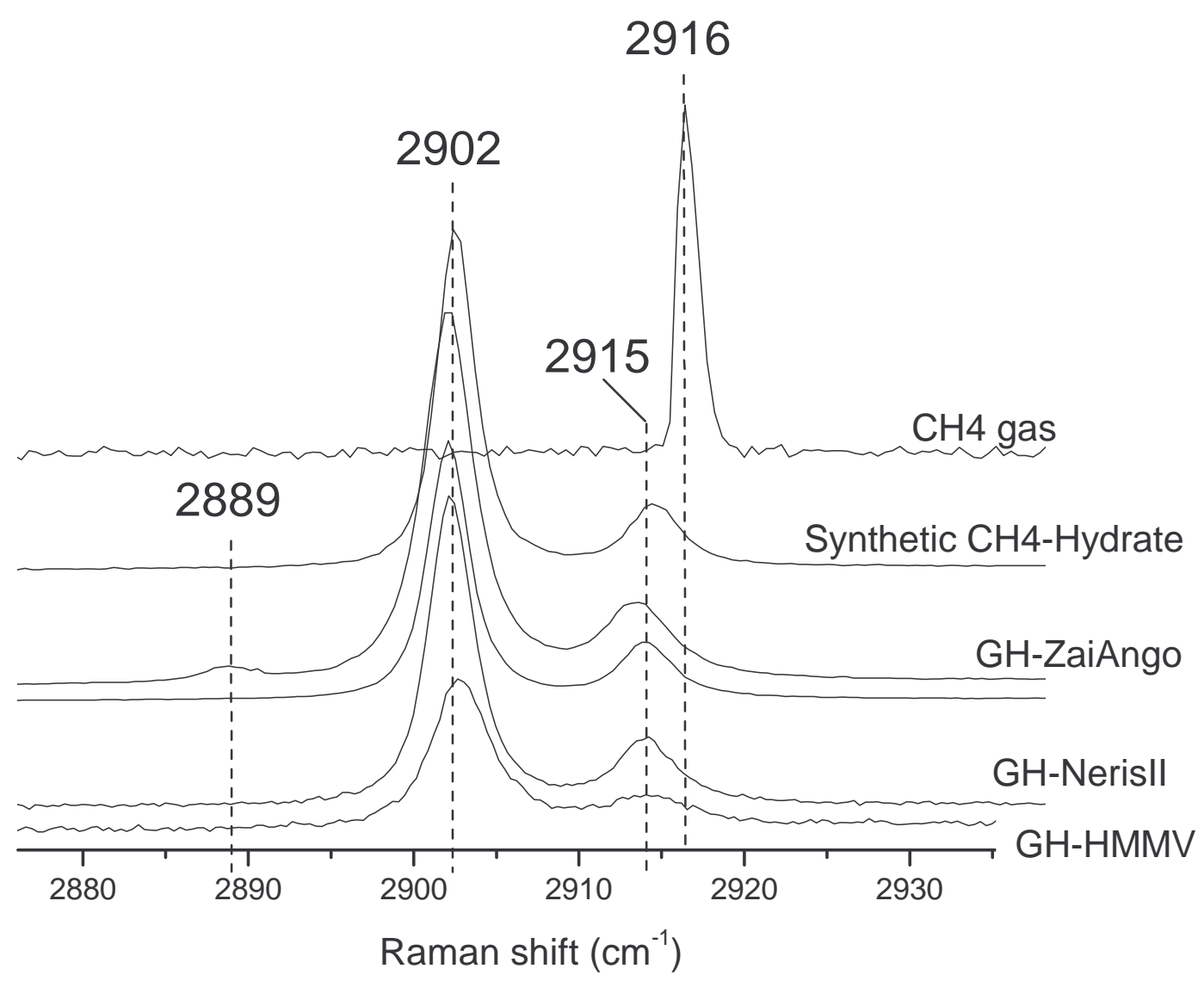


FIGURE 3: Comparative spectra of the $\mathrm{O}-\mathrm{H}$ spectral region of water at $\sim 3100 \mathrm{~cm}^{-1}$. The weak additional component at $~ 3053 \mathrm{~cm}^{-1}$ characterizes the presence of hydrates. It is assigned to an overtone of methane (see text). Its presence is confirmed on the spectra of the $\mathrm{CH}_{4}$ deuterohydrate where the contribution of water molecules (O-D stretching) are absent from the spectral region. Variations in the O-H band position is due to differences in temperature and/or reflect the structural differences between ice and hydrate which are both present in variable amounts under the laser spot. The spectra of methane in the free gas phase is shown for comparison (see discussion).

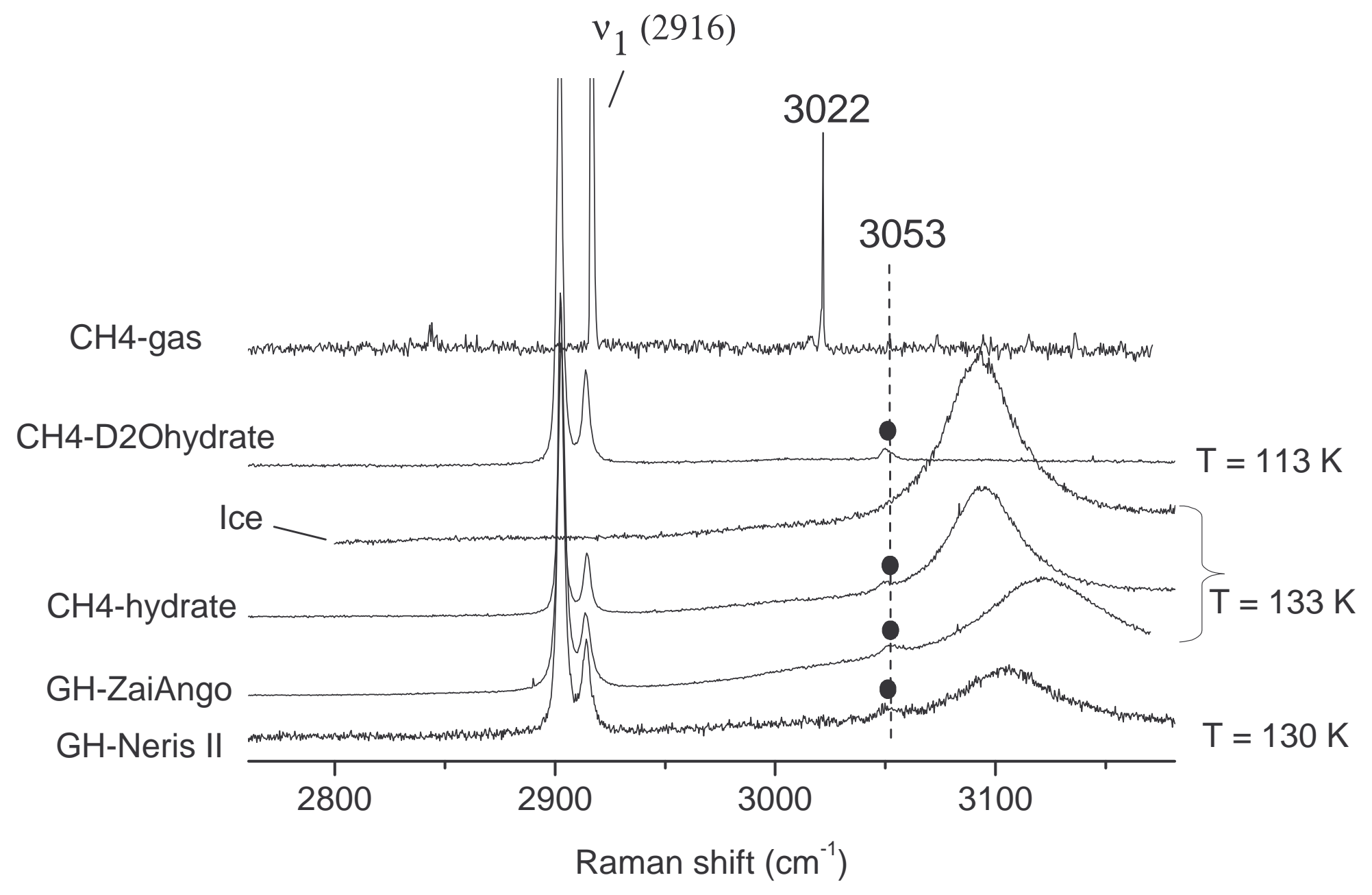


FIGURE 4: Comparative Raman spectra corresponding to the H-S spectral region. A unique component is observed for the gas hydrate from ZaiAngo and the synthetic $\mathrm{CH}_{4}$-hydrate at $2570 \mathrm{~cm}^{-1}$, whereas an additional component at $\sim 2593 \mathrm{~cm}^{-1}$ appears in the Neris II hydrate. This latter matches well that observed in the synthetic $\mathrm{H}_{2} \mathrm{~S}$-hydrate (see text for the assignment). The inset shows the characteristic spectral lines of $\mathrm{CO}_{2}$-clathrate $\left(v_{1}\right.$ and $2 v_{2}$ stretching and overtone of the bending, respectively) observed in the ZaiAngo-hydrate. The vertical doted lines represent the approximate positions of the corresponding bands expected for $\mathrm{CO}_{2}$ in the gas phase.

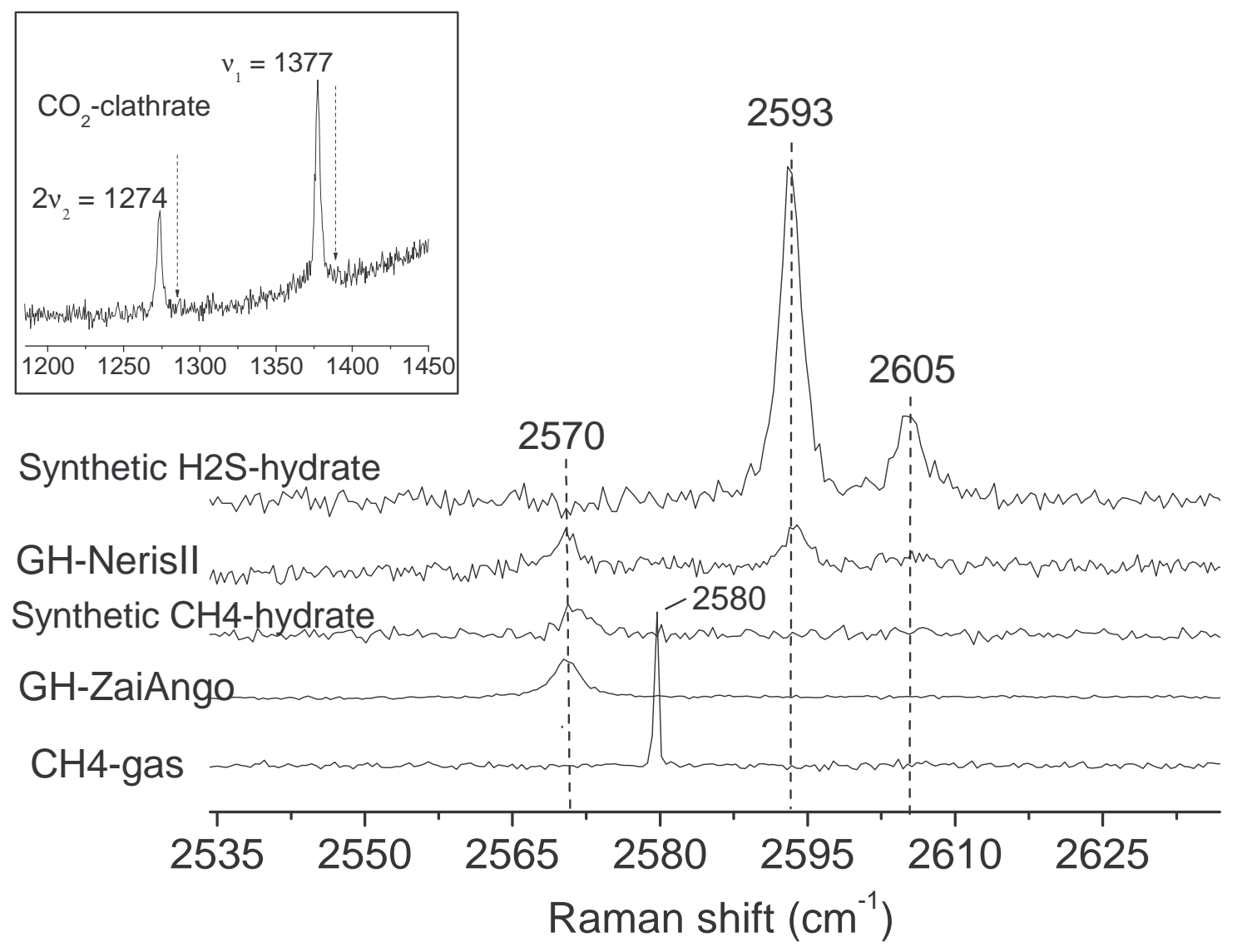


Table 1: Relative cage occupancy of methane trapped in the hydrate structure I as determined from Raman band corresponding to C-H stretching.

\begin{tabular}{cc}
\hline Hydrate & $\theta_{\mathrm{SC}} / \theta_{\mathrm{LC}}$ \\
\hline ZaiAngo & $0.86 \pm 0.03$ \\
Neris II & $0.81 \pm 0.02$ \\
$\mathrm{HMMV}$ & $0.8 \pm 0.1$ \\
$\mathrm{CH}_{4}$-hydrate & $0.78 \pm 0.02$ \\
$\mathrm{H}_{2}$ S-hydrate & $0.95 \pm 0.1$ \\
\hline
\end{tabular}


Table 2: Wavenumbers and assignments of the Raman bands of $\mathrm{CH}_{4}$ and $\mathrm{H}_{2} \mathrm{~S}$ in the gas phase and in the hydrate phase

\begin{tabular}{|c|c|c|c|}
\hline Gas Component & $\begin{array}{l}\text { Assignment } \\
\text { proposed }^{\text {a }}\end{array}$ & Symmetry & Hydrate sI (this work) \\
\hline $\mathrm{CH}_{4} / \mathrm{v}\left(\mathrm{cm}^{-1}\right)^{\mathrm{b}}$ & & $\mathrm{T}_{\mathrm{d}}$ point group & $\mathrm{CH}_{4} / \mathrm{v}\left(\mathrm{cm}^{-1}\right)$ \\
\hline $1306(\mathrm{I})$ & $\underline{v}_{4}$ bending & $F_{2}$ & -- \\
\hline $1540(\mathrm{R})$ & $\underline{v}_{2}$ antisym. bend & $E$ & -- \\
\hline 2605 & $2 v_{4}$ overtone & $A_{1}+E+F_{2}$ & 2570.2 \\
\hline \multirow[t]{2}{*}{$2917(\mathrm{R})$} & $\underline{v}_{1}$ sym. C-H & $A_{1}$ & 2902.4 (LC) \\
\hline & & & $2914.5(\mathrm{SC})$ \\
\hline 3020 (I / R) & $\begin{array}{l}\underline{v}_{3} \text { antisym. C-H } \\
\text { stretching }\end{array}$ & $F_{2}$ & -- \\
\hline $3070(\mathrm{R})$ & $2 v_{2}$ overtone & $A_{1}+E$ & 3052.7 \\
\hline $\mathrm{H}_{2} \mathrm{~S} / \mathrm{v}\left(\mathrm{cm}^{-1}\right)^{\mathrm{b}}$ & & $\mathrm{C}_{2 \mathrm{v}}$ point group & $\mathrm{H}_{2} \mathrm{~S} / \mathrm{v}\left(\mathrm{cm}^{-1}\right)$ \\
\hline 1183 & $\underline{v}_{2}$ bending & $A_{1}$ & -- \\
\hline 2611 & $\begin{array}{l}\underline{v}_{1} \text { sym. H-S } \\
\text { stretching }\end{array}$ & $A_{1}$ & 2593.4 (LC) \\
\hline$(2627)$ & $\begin{array}{l}\underline{\mathrm{v}}_{3} \text { antisym. } \\
\text { stretching }\end{array}$ & $B_{2}$ & $\begin{array}{c}2605.1(\mathrm{SC}) \\
--\end{array}$ \\
\hline
\end{tabular}

${ }^{a}$ Gas phase, fundamentals internal modes are underlined

${ }^{b}$ theoretical in parenthesis (Nakamoto, 1978), observed by Raman = R, by Infrared $=$ I 